Research Article

\title{
Assessment of drug prescribing pattern using WHO indicators in hospitalized patients at a tertiary care teaching hospital in rural area of India
}

\author{
Asha Pathak ${ }^{1 *}$, Vinay Kumar Gupta ${ }^{1}$, Arvind Maurya ${ }^{1}$, Alok Kumar ${ }^{2}$, Amit Singh ${ }^{3}$
}

\begin{abstract}
${ }^{1}$ Department of Pharmacology, UP Rural Institute of Medical Sciences \& Research, Saifai, Etawah, Uttar Pradesh, India. ${ }^{2}$ Department of Forensic Medicine, UP Rural Institute of Medical Sciences \& Research, Saifai, Etawah, Uttar Pradesh, India.

${ }^{3}$ Department of Microbiology, UP Rural Institute of Medical Sciences \& Research, Saifai, Etawah, Uttar Pradesh, India
\end{abstract}

Received: 18 March 2016 Accepted: 01 April 2016

\section{*Correspondence to: \\ Dr. Asha Pathak, \\ Email: drasha_pathak \\ @yahoo.co.in}

Copyright: (c) the author(s), publisher and licensee Medip Academy. This is an openaccess article distributed under the terms of the Creative Commons Attribution NonCommercial License, which permits unrestricted noncommercial use, distribution, and reproduction in any medium, provided the original work is properly cited.

\begin{abstract}
Background: To promote rational drug use in patients of rural areas, it is important to assess drug use pattern using the WHO prescription indicators. The aim of this study was to assess the drug prescription patterns in patients admitted in Medicine department of UPRIMS\&R.

Methods: A prospective observational study was conducted from Jan 2015 to June 2015. Data were collected \& analysed according to WHO prescribing indicators and presented by using descriptive statistics.

Results: 626 prescriptions were selected in which 3205 drugs were prescribed. The most common drug groups prescribed were antibiotics $24.64 \%$ followed by anti-diabetic drugs $12.38 \%$, analgesics $12.23 \%$ and drugs for cardiovascular diseases $11.82 \%$, GIT drugs $9.01 \%$. Average number of drugs per prescription was 5.11. Drugs prescribed from essential drugs list (India) was 76.06\%. Drugs prescribed from essential drugs list (WHO) was $23.04 \%$. Total number of prescriptions with antibiotics was $24.27 \%$. Total number of prescriptions with injections was $24.05 \%$. Percentage of fixed dose combinations was $28.7 \%$. Drugs prescribed by generic name were $89.88 \%$.

Conclusions: The prescribing pattern of antibiotics was according to WHO recommendations while the average number of drugs per prescription was found high. There were small differences in the values of drugs prescribed by generic names, injectable and drugs from NLEM from the recommended values.
\end{abstract}

Keywords: Prescribing indicators, Rational drug, EDL, Prescribing pattern, Prescriptions, WHO

\section{INTRODUCTION}

Assessment of use of drugs is a system of ongoing criteria-based drug evaluation system that ensures the appropriate use of drugs. ${ }^{1}$ Drug use is complex subject which includes patients, physicians and dispensers who may be influenced by various factors which are often difficult to measure or quantify. WHO has developed, standardized and evaluated a number of indicators which are grouped in to three categories namely: prescribing indicators, patient care indicators and facility indicators. ${ }^{2}$ Throughout the world, information on drug use is limited which indicates that drugs are not used optimally and this inappropriate use has serious health and economic consequences which is not beneficial for the success of national health care system. The irrational use of drugs 
becomes the world wide problem than the absence of drugs information. Even drug experts (pharmacists) have also contributed to the irrational use of drugs in a world wide scale, encompassing developing and developed countries, developing countries have rather worsened condition. ${ }^{3}$ The label on dispensed medicines should provide the patient with all the information necessary so that the medication can be taken or used appropriately, as result therapeutic effectiveness of the drug will be improved and toxicity and adverse drug reaction will be reduced. ${ }^{4}$ Globally, more than $50 \%$ of all medicines are prescribed, dispensed or sold inappropriately, while $50 \%$ of patients fail to take the prescribed drugs correctly and one third of the world population lacks access to essential medicines. ${ }^{5}$ Studies reported from various areas of the world reveal different drug use patterns. ${ }^{6-9}$ Irrational use of medicines can stimulate inappropriate patient demand and lead to reduced access and attendance rates due to medicine stock outs and loss of patient confidence in health. ${ }^{5}$ Essential drug ones selected to fulfill the real need of the majority of the population in diagnostic, prophylactic, therapeutic and rehabilitative services using criteria of risk benefit ratio, cost effectiveness, quality practical administration as well as patient compliance and acceptance. $^{10}$

Generally, irrational drug use are numerous and complex involving the health system, prescriber, dispenser, patient and the community. Due to such worsened condition, it is now felt that the overall drug use situation needs to be assessed, problems identified and remedial intervention strategies to be implemented. The current study is, therefore, aimed at assessing patterns of drug use by using WHO prescribing indicators.

\section{WHO prescribing indicators}

1. Average number of drugs per encounter: Average, calculated by dividing the total number of different drug products prescribed, by the number of encounters surveyed. It is not relevant whether the patient actually received the drugs.

2. Percentage of drugs prescribed by generic name: Percentage, calculated by dividing the number of drugs prescribed by generic name, by the total number of drugs prescribed, multiplied by 100 .

3. Percentage of encounters with an antibiotic prescribed: Percentage, calculated by dividing the number of patient encounters during which an antibiotic is prescribed, by the total number of encounters surveyed, multiplied by 100 .

4. Percentage of encounters with an injection prescribed: Percentage, calculated by dividing the number of patient encounters during which an injection is prescribed, by the total number of encounters surveyed, multiplied by 100 .
5. Percentage of drugs prescribed from essential drugs list or formulary: Percentage, calculated by dividing the number of products prescribed which are listed on the essential drugs list or local formulary (or which are equivalent to drugs on the list).

\section{Aim \& objectives}

The present study was undertaken with an aim to develop baseline data on drug prescribing pattern and to evaluate the rationality of the prevalent prescribing pattern by using WHO prescribing indicators.

\section{METHODS}

After obtaining approval from Institutional Research Committee, a prospective observational study was conducted in hospitalized patients in medical department of Uttar Pradesh Rural Institute of Medical Sciences \& Research (UP RIMS \& R), Saifai, District Etawah, Uttar Pradesh, India. Study period was Jan 2015 to June 2015.

All inpatient case records selected randomly were analyzed for prescriptions. Only drugs of modern medicine were included in the study. Intravenous fluids and transfusions were not counted as drugs. Data were collected in a study proforma from case records. Study proforma contained demographic data, disease data and drug data of the patients. Data were analyzed according to WHO prescribing indicators and presented by using descriptive statistics namely total numbers, mean and percentage wherever applicable.

\section{RESULTS}

A total of 626 prescriptions were selected in which 3205 drugs were prescribed. The demographic profiles of the patients showed that up to age of $20 \mathrm{yrs}$, it was $15.81 \%$, (21-40 years) were $29.06 \%$, (41-60 years) were $26.52 \%$, (61-80 years) were $19.32 \%$ and $>80$ age group were constituted $9.26 \%$ (Figure 1).

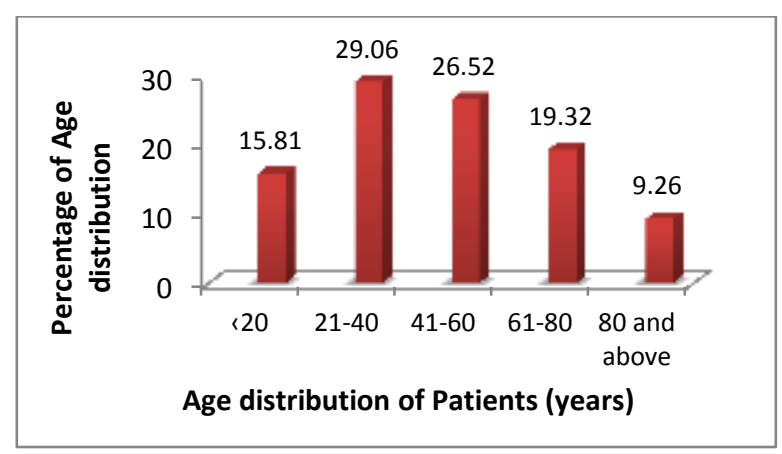

Figure 1: Age distribution of patients.

The proportions of males were higher $63.01 \%$ as compared to females $36.09 \%$ (Figure 2). The most common route used were oral $(71.03 \%)$ followed by parenteral $(24.05 \%)$ and topical $(4.92 \%)$ (Figure 3$)$. 


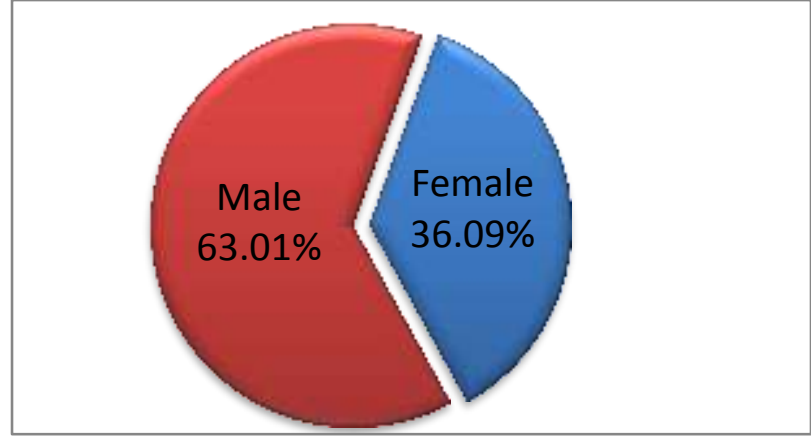

Figure 2: Percentage of sex distribution.

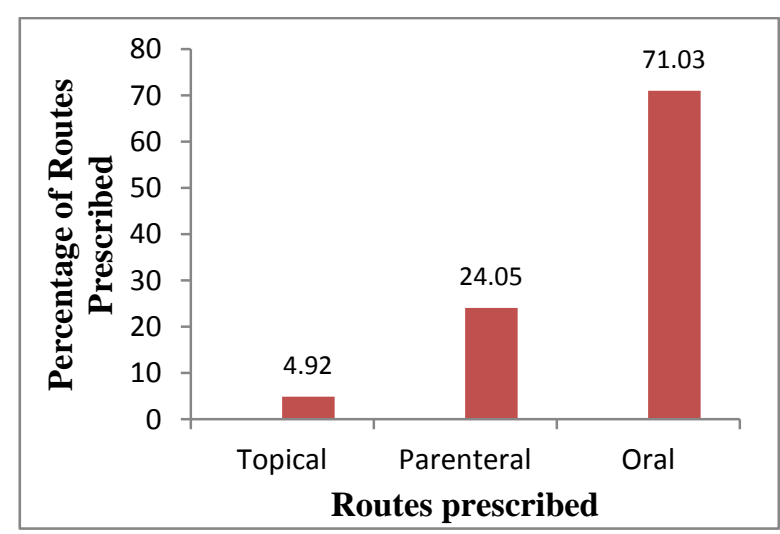

Figure 3: Common routes prescribed.

Average number of drugs per encounter was 5.11. Drugs prescribed from essential drugs list (India) was 76.06\%. Drugs prescribed from essential drugs list (WHO) was 23.04\%. Total number of prescriptions with injections was $24.05 \%$. Percentage of fixed dose combinations was $28.7 \%$. Drugs prescribed by generic name were $89.88 \%$ (Figure 4 and Table 1).

Table 1: Prescribing indicators.

\begin{tabular}{|ll|}
\hline Parameters & Observed value \\
\hline $\begin{array}{l}\text { Total number of prescriptions } \\
\text { analyzed }\end{array}$ & 626 \\
\hline Total number of drugs prescribed & 3205 \\
\hline $\begin{array}{l}\text { Average number of drugs per } \\
\text { encounter }\end{array}$ & 5.11 \\
\hline Drugs prescribed by generic name & $89.88 \%$ \\
\hline $\begin{array}{l}\text { Drugs prescribed from essential } \\
\text { drugs list (India) }\end{array}$ & $76.06 \%$ \\
\hline $\begin{array}{l}\text { Drugs prescribed from essential } \\
\text { drugs list (WHO) }\end{array}$ & $23.04 \%$ \\
\hline $\begin{array}{l}\text { Total number of prescriptions with } \\
\text { antibiotics }\end{array}$ & $24.27 \%$ \\
\hline $\begin{array}{l}\text { Total number of prescriptions with } \\
\text { injections }\end{array}$ & $24.05 \%$ \\
\hline $\begin{array}{l}\text { Percentage of Fixed Dose } \\
\text { Combinations }\end{array}$ & $28.7 \%$ \\
\hline
\end{tabular}

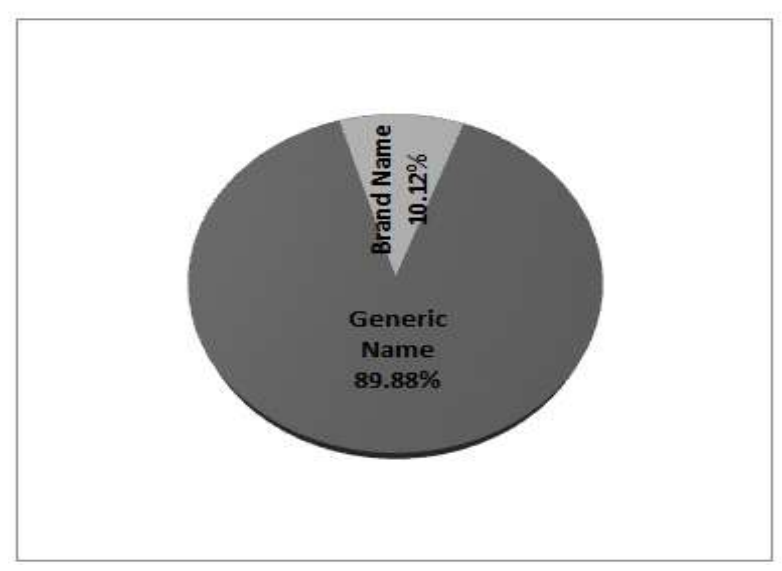

Figure 4: Percentage of drugs prescribed by brand and generic name.

The most common drug groups prescribed were antibiotics $24.27 \%$ followed by anti-diabetic drugs $12.38 \%$, analgesic $12.23 \%$, CVS drugs $11.82 \%$, GIT drugs $9.01 \%$ respectively (Figure 5).

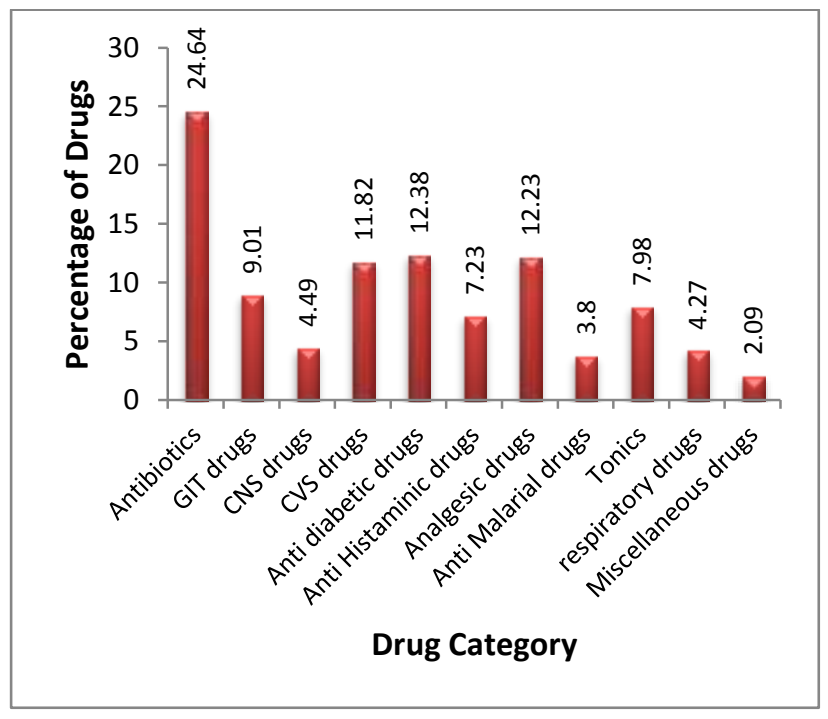

Figure 5: Percentage of drug categories.

The incidence of polypharmacy was also common with range of 2 to 8 drugs per prescription. 32 prescriptions had two drugs per prescription. $22.68 \%$ of prescriptions had 4 drugs, $18.21 \%$ had 5 drugs and $15.81 \%$ had 6 drugs per prescription. More than 8 drugs were prescribed in $2.87 \%$ prescriptions. Prescriptions contained 4 or more drugs were about $87 \%$ (Table 2).

Most of the patients had chronic liver diseases $14.06 \%$, followed by diabetes mellitus $13.88 \%$, diarrhoea $11.22 \%$, coronary artery diseases $12.17 \%$, chronic kidney disease $10.07 \%$, cirrhosis $8.75 \%$, and hepatitis $8.37 \%$ (Figure 6). 
Table 2: Incidence of poly pharmacy.

\begin{tabular}{|lll|}
$\begin{array}{l}\text { No. of drugs } \\
\text { prescribed } \\
\text { per prescription }\end{array}$ & No. of prescription & Percentage \\
\hline 2 & 32 & 5.11 \\
\hline 3 & 49 & 7.82 \\
\hline 4 & 142 & 22.68 \\
\hline 5 & 114 & 18.21 \\
\hline 6 & 99 & 15.81 \\
\hline 7 & 88 & 14.05 \\
\hline 8 & 84 & 13.41 \\
\hline$>8$ & 12 & 2.87 \\
\hline
\end{tabular}

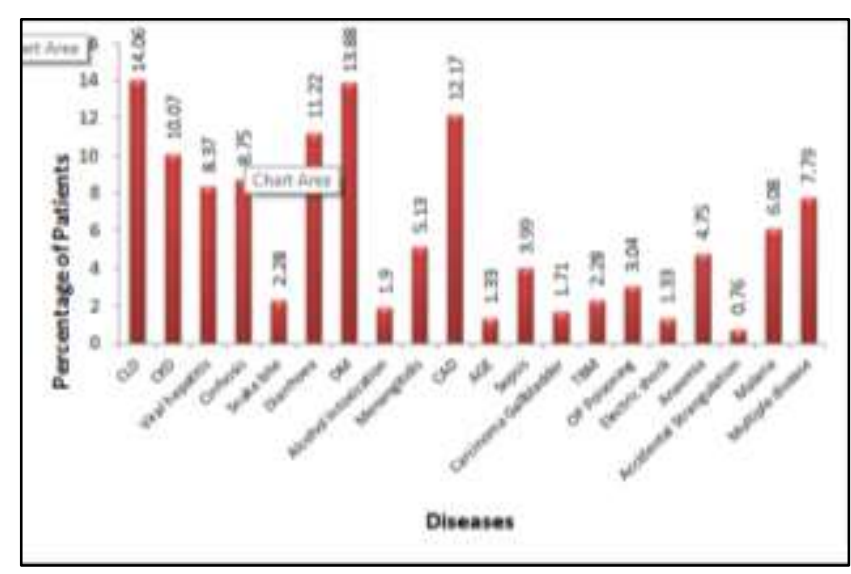

Figure 6: Percentage of patients with diseases.

\section{DISCUSSION}

Prescription auditing is important tool for quality assurance in hospitals. They should address problems that have serious consequences for patients if proper treatment is not given. The audit data will be of great value to health care providers, for their decision making and drafting policies.

In present study, 626 prescriptions were analyzed, contained 3205 drugs. Therefore average number of drugs per prescriptions was found 5.11. This value is similar to study done by Harmeet et al, 199811 and N. Meena et al, 2013. ${ }^{12}$ This is much higher than the recommended limit of 2.0. This value is also higher in studies done by Afroz et al, 2012 (4.22), ${ }^{13}$ P. Geetha et al, 2015 (4.38). ${ }^{14}$ Increase in the number of average drugs per prescription may increase the risk of drug interactions, \& may lead to unwanted adverse effects. It also increases the cost of treatment and increased chances of emergence of resistance.

Drugs prescribed by generic names were only in $89.88 \%$ of cases. Although this is low as compared to standard value $100 \%$ but is higher than study done by Nitti et al, $2014(21.55 \%),{ }^{15}$ Afroz et al, $2012(3.79 \%),{ }^{13} \mathrm{~N}$ Meena et al, $2013(3.64 \%)^{12}$ and Binu et al, $2013(14.83 \%) .{ }^{16}$ The low values of generic drug use in the above studies shows how prescribing habits are being directly influenced by the representative of the drugs companies for undue favours but this is not applicable in our study. Generic prescribing reduces the chances of dispensing errors which may be due to misinterpretation of like sounding names of drugs and also decreases the economic burden on the patients. Hence we should encourage generic prescribing. Drugs from NLEM were only $76.06 \%$. Though it is comparable with other Indian studies, (78\%) in study by Nitti et al, $2014^{15}(70.26 \%)$ by Binu et al, $2013^{16}$ but was still on the lower side as compared to standard value and study done by U.K. Chandelkar et al., $2014(99.67 \%) .{ }^{17}$ Also the percentage of drugs prescribed from the essential drugs list of WHO was only $23.03 \%$. This may be due to lack of awareness of essential drug list. Injectables were used in $(24.05 \%)$ of prescription. Though the use of injectables were high as compared to standard value (less than 10\%) but was lower than studies done by N. Meena et al, $2013(59.1 \%)^{12}$ and by P. Geetha et al, $2015(38 \%)^{14}$

Antibiotics prescribed were $24.27 \%$ out of all drugs. According to WHO $15-25 \%$ of prescriptions with antibiotics are expected in most of the developing countries where infectious diseases are more prevalent. This figure was within the standard limits however figure was very high $(59.1 \%)$ in study done by N. Meena et al, 2013. ${ }^{12}$ Appropriate use of antibiotics is absolutely necessary to prevent emergence of drug resistance and should be used after culture sensitivity testing. Most of the acute respiratory and acute gastroenteritis cases are due to viral infection and may not need antibiotics. An antibiotic policy should be formulated so that the clinicians can use them judiciously according to patients need.

Poly pharmacy was clearly visible in our study. Maximum number of prescriptions i.e. $22.68 \%$ had four drugs each followed by five drugs in $18.21 \%$ and six drugs in $(15.81 \%)$, seven drugs in $(14.05 \%)$ and eight drugs in $(13.41 \%)$ of prescription. Poly pharmacy is a very common practice now days as is reported by various studies (Binu et al, 2013, Afroz et al, 2012 and Niti et al, 2014). ${ }^{13,15,16}$ It is of concern in those patients with various co-morbidities as it increases the chances of drug interactions \& adverse effects.

The most common disease pattern seen in patients was chronic liver diseases accounting for $(14.06 \%)$ of cases followed by diabetes mellitus \& coronary artery disease which were accounting for $(13.88 \%)$ and $(12.17 \%)$ of cases.

The most common categories of drugs prescribed were; antibiotics $(24.64 \%)$ followed by anti-diabetics $(12.38 \%)$ and analgesics $(12.23 \%)$. The ideal value of percentage of prescription with antibiotics is less than $30 \%$. In our study percentage prescription of antibiotic was according to ideal value. Similar value was also present in study done by Afroj Abidi et al, $2012^{13}$ but its values were 
higher in studies done by Binu et al, 2013 (41.98\%), U.A. Chandelkar et al, $2014(31.8 \%),{ }^{17}$ Harmeet et al, $1998(42.8 \%) .{ }^{11}$ Drugs for CVS were prescribed in (11.82 $\%)$, followed by drugs for GIT ailments $(9.01 \%)$. Tonics and antihistaminic were prescribed in $7.98 \%, 7.23 \%$ of cases respectively. Expectorants \& bronchodilators were prescribed in $4.27 \%$ of cases.

It's required to reduce the unnecessary use of injectables to prevent HIV and other blood borne infections. Medicines like multivitamins, minerals, enzymes should not be prescribed by physicians unless absolutely required by the patient. It will increases the cost of therapy and increases the chances of drug interactions.

\section{CONCLUSIONS}

The present study showed the prescribing pattern of antibiotics was according to WHO recommendations while the average number of drugs per prescription was found high. There were small difference in the values of drugs prescribed by generic names, injectable and drugs from NLEM from the recommended values; hence there is a need to improve the standard of prescription. This can be achieved by educating and updating clinicians through CME, seminar by providing them standard treatment guidelines, essential drug list and antibiotic policy.

\section{ACKNOWLEDGMENTS}

Authors are acknowledging Institutional Research Committee for approval and Head of Department and faculties of Department of Medicine, UPRIMS\&R, Saifai, Etawah, for providing support \& facilities.

Funding: No funding sources

Conflict of interest: None declared

Ethical approval: The study was approved by the Institutional Ethics Committee

\section{REFERENCES}

1. WHO, rational drug use, dispensing, prescribing, counseling and adherence in ART programs. Conference express in Nairobi, 1995.

2. WHO, how to investigate drug use in health facilities in selected drug use indicator, EDM. Research series, No 07, 1993.

3. Managing drug supply. Management science for health. $2^{\text {nd }}$ ed. West Hariford, Connecticut, Kumar press; 1997:138-479.

4. Aulton EM, Collet MD. Pharmaceutical practice. Churchill Livingston, United Kingdom; 1990:73-4.
5. WHO, policy perspective on medicines; promoting rational use of medicines; core components, Geneva. 2002.

6. Desta Z, Abula T, Beyene L, Fantahun M, Yohannes AG, Ayalew S. Assessment of rational drug use and prescribing in primary health care facilities in North West Ethiopia. East African Med J. 1997;74:758-63.

7. Dikaso D, Gobe Z, Teklemariam S. A base line survey on prescribing indicators and underlying factors influencing prescribing in southern Ethiopia. Ethiopia J Health Dev. 1998;12(2):87-93.

8. Mallet HP, Njikam A, Scouflaire SM. Evaluation of prescription practices and the rational use of medicines in Niger. Niger Pharm J. 2001;11(3):18596.

9. Otoom S, Batieha A, Hadidi H, Hasan M, Al Saudi K. Evaluation of drug use in Jordan using World Health Organization prescribing indicators. Eastern Mediterranean Health J. 2002;8:544-9.

10. Hogerzeil HV. Promoting rational prescribing: an international perspective. $\mathrm{Br} \mathrm{J}$ Clin Pharmacol. 1995;39(1):1-6.

11. Rehana HS, Nagarani MA, Rehan M. A study on the drug prescribing pattern and use of antimicrobial agents at a tertiary care teaching hospital in Estern Nepal. Indian J Pharmacol. 1998;30:175-80.

12. Meena N, Rita S, Sania MKH, Gunaseelan V, Thangkhiew B. Drug prescription pattern in a tertiary health centre in Imphal-a cross sectional study. Int J Pharm B Sci. 2013;4(4):P838-42.

13. Abidi A, Gupta S, Kansal S, Ramgopal. Prescription auditing and drug utilization pattern in a tertiary care teaching hospital of western UP. Intern J Basic \& Clin Pharmacol. 2012;1(3):184.

14. Geetha P, Vijaylakshami P, Tilak S, Maheshwaran A, Naraynan N. Prescription analysis to evaluate the rational use of drugs by using WHO health care indicators. Intern J Multidiscipl Res Develop. 2011;2(5):358-60.

15. Mittal N, Mittal R, Singh I, Shafiq N, Malhotra S. Drug utilization study in a tertiary care center, Recommendations for improving hospital drug dispensing policies. Indian $\mathbf{J}$ Pharmaceut Sci. 2014;76(4):308-14.

16. Mathew B, Rahul S, Kumar S, Doddayya $H$. Assessment of drug prescribing practices using WHO prescribing indicators in a private tertiary care teaching hospital. Intern Res J Invent Pharmaceut Sci. 2013;1(2):26-30.

17. Chandelkar UK, Rataboli PV. A study of drug prescribing pattern using WHO prescribing indicators in the state of Goa, India. Intern J Basic Clin Pharmacol. 2014;3(6):1057-61.

Cite this article as: Pathak A, Gupta VK, Maurya

A, Kumar A, Singh A. Assessment of drug prescribing pattern using WHO indicators in hospitalized patients at a tertiary care teaching hospital in rural area of India. Int J Basic Clin Pharmacol 2016:5:651-5. 